\title{
The Patient's Experience of Ocular Melanoma in the US: A Survey of the Ocular Melanoma Foundation
}

\author{
Armin R. Afshar ${ }^{a}$ Michael Deiner ${ }^{a}$ Grant Allen $^{b}$ Bertil E. Damato ${ }^{a, c}$ \\ ${ }^{a}$ Department of Ophthalmology, University of California, San Francisco, San Francisco, CA, ${ }^{b}$ Ocular Melanoma \\ Foundation, Washington, DC, ' Department of Radiation Oncology, University of California, San Francisco, \\ San Francisco, CA, USA
}

\section{Keywords}

Ocular melanoma - Uveal melanoma · Conjunctival

melanoma · Treatment · Counseling · Quality of life

\begin{abstract}
Background: Ocular melanomas threaten patients with early death, visual handicap, and loss of the eye. The aims of this study were to identify aspects of care that patients with ocular melanoma considered most important and to determine whether patients felt their needs had been adequately addressed. Methods: A cross-sectional study including US ocular melanoma patients and their caregivers. An online survey of US ocular melanoma patients was designed and conducted by the Ocular Melanoma Foundation. Results: The cohort included 180 patients with uveal melanoma and 4 with conjunctival melanoma. Median follow-up was 3 years. A third of patients reported that their uveal melanoma had initially been diagnosed as a nevus. Most uveal melanomas were treated with brachytherapy. Almost $50 \%$ of patients had no genetic tumor analysis. Screening methods reported most commonly were computed tomography and liver function tests. Metastatic disease developed in $11 \%$ of patients. Few patients (13.3\%) reported an offer of psycho-
\end{abstract}

() 2018 S. Karger AG, Basel logical support. Most dissatisfaction was with lack of advice on financial aspects of care and lack of psychological counseling, with women tending to express more dissatisfaction with care. Many patients complained about the way ophthalmologists delivered bad news to them. Conclusions: This patients' perspective highlights directions for research, education, and other measures to improve the care of patients with ocular melanoma in the US and elsewhere.

(c) 2018 S. Karger AG, Basel

\section{Introduction}

Approximately $95 \%$ of ocular melanomas are intraocular, the remainder arising in conjunctiva. Both types threaten patients with premature death, visual handicap, loss of the eye, facial disfigurement, impaired social function, and loss of independence.

The patient's care pathway involves many stages: detection, diagnosis, treatment, prognostication, systemic surveillance, and treatment for metastatic disease. Other aspects of care include informed consent, emotional support, psychological counseling, and education on the possible impact of the disease on the patient's way of life.

\section{KARGER}

E-Mail karger@karger.com

www.karger.com/oop
Armin R. Afshar, MD, MBA

Department of Ophthalmology, University of California, San Francisco

10 Koret Way, K-304, Box 0730

San Francisco, CA 94143 (USA)

E-Mail Armin.Afshar@ucsf.edu 
There is vast scientific literature on all these topics, but to our knowledge there are no studies providing ocular melanoma patients' perspective on their particular needs and how well these are met.

The aims of this study were to identify aspects of care that patients with ocular melanoma considered most important and to determine whether patients felt their needs had been adequately addressed.

\section{Methods}

An online survey was designed by members of the Ocular Melanoma Foundation (OMF), a patient advocacy organization. Survey participants were invited via email to OMF network participants on April 15, 2015. A survey link was also posted on social media (Facebook). OMF network members were verified by the OMF as patients with ocular melanoma. The online survey (SurveyMonkey, Palo Alto, CA, USA) was active for 2 weeks. 159 respondents accessed the link through the Constant Contact email and 153 through Facebook.

Patients were asked only for their year of birth, to preserve confidentiality. De-identified results were sent to authors (A.R.A., M.D., B.E.D.) at the University of California, San Francisco. Data analysis was performed using SPSS (SPSS Inc., Chicago, IL, USA). This study was exempted by the UCSF Institutional Review Board.

A total of 128 questionnaires were excluded because the patient did not reside in the US $(n=38)$, because the questionnaire was completed by a caregiver on their behalf $(n=51)$, and/or because the patient did not report the tumor location $(n=73)$.

\section{Results}

\section{Patients with Uveal Melanoma}

The 180 patients with uveal melanoma (130 women, 50 men) had a median age of 58 years (range, 26-81) when they completed the questionnaire. The tumor involved choroid in 167 (92.7\%) patients, ciliary body in 9 (5.0\%), and iris in 4 (2.2\%). The follow-up time between diagnosis and questionnaire had a median of 3.0 years (range, 0.12-24.6).

\section{Detection}

One hundred and twelve (62.6\%) of 179 patients answering the questions (i.e., 179 "respondents") were initially informed of their tumor by an ophthalmologist and $55(30.7 \%)$ by an optometrist, with 12 (6.7\%) reporting another provider. Mydriasis was reported by 151 (90.4\%) of 167 patients with posterior uveal melanoma, with 13 (7.8\%) stating that their pupils were not dilated and 3 $(1.8 \%)$ not answering. Immediate referral to an ocular oncologist was reported by 151 (87.8\%) of 172 respondents.

\section{Diagnosis}

The tumor was diagnosed by an ocular oncologist in 148 (84.6\%) of 175 respondents, by another ophthalmologist in $21(12.0 \%)$, and another practitioner in $6(3.4 \%)$. The distance traveled to this practitioner exceeded 250 miles in 33 (18.5\%) patients. The time between tumor detection and diagnosis exceeded 4 weeks in $34(19.1 \%)$ patients. Of 160 respondents, $53(33.1 \%)$ reported that their melanoma had previously been diagnosed as a nevus. In these patients, surveillance exceeded 36 weeks in 28 (51\%).

\section{Ocular Treatment}

In 174 respondents, ocular treatment was plaque brachytherapy in $136(78.2 \%)$, proton beam radiotherapy in $17(9.8 \%)$, enucleation in $18(10.3 \%)$, stereotactic radiotherapy in $1(0.6 \%)$, transpupillary thermotherapy in $1(0.6 \%)$, and excision in 1 patient $(0.6 \%)$.

Of 176 patients with a posterior uveal melanoma, 110 $(62.5 \%)$ reported their tumor thickness at the time of treatment, which was categorized as $\leq 3.0 \mathrm{~mm}$ in 27 $(40.6 \%)$ of these, $3.1-6.0 \mathrm{~mm}$ in $27(40.6 \%)$, and $>6.0 \mathrm{~mm}$ in $13(18.8 \%)$. One patient mentioned receiving 3 different thickness estimates from 3 specialists.

Treatment was received within 1 week of diagnosis in 39 (22.2\%) of 176 respondents, $1-2$ weeks from diagnosis in $33(18.8 \%)$ and more than 4 weeks from diagnosis in $46(25.6 \%)$.

Receiving information on plaque brachytherapy was reported by $158(87.8 \%)$ patients, enucleation by 102 (56.7\%), proton beam radiotherapy by $48(26.7 \%)$, and transpupillary thermotherapy by 20 (11.1\%).

Eleven $(6.7 \%)$ of 165 respondents reported tumor recurrence, after brachytherapy (9), proton beam radiotherapy (1), and enucleation (1), respectively, with the time to recurrence exceeding 3 years in 6 out of the 8 patients providing this information. Enucleation more than 3 months after primary ocular treatment was reported by 11 patients.

\section{Prognostic Biopsy}

Of 164 respondents, 102 (62.2\%) reported that they had received information on biopsy. Gene expression profiling (GEP) was discussed by $38(26.2 \%)$ patients, chromosome 3 testing by 28 (15.6\%), multiplex ligationdependent probe amplification/microsatellite (MLPA/ MSA) analysis by 4 (2.2\%), GNAQ/11 by 3 (1.7\%), Foundation 1 testing by $2(1.1 \%)$, and single nucleotide polymorphism (SNP) analysis by $1(0.6 \%)$.

With regard to the test performed, in 158 respondents, GEP was mentioned by 42 (23.3\%), monosomy 3 by 29 
Table 1. Patient's satisfaction with experience of care

\begin{tabular}{|c|c|c|c|c|}
\hline Patient's experience & Sex & $\begin{array}{l}\text { Dissatisfied } \\
n(\%)\end{array}$ & $\begin{array}{l}\text { Satisfied } \\
n(\%)\end{array}$ & $\begin{array}{l}p \\
\text { value }^{\mathrm{a}}\end{array}$ \\
\hline $\begin{array}{l}\text { Financial counseling/guidance on how to pay for my cancer } \\
\text { treatment }\end{array}$ & $\begin{array}{l}\text { female } \\
\text { male }\end{array}$ & $\begin{array}{l}48(84.2) \\
11(47.8)\end{array}$ & $\begin{array}{r}9(15.8) \\
12(52.2)\end{array}$ & 0.001 \\
\hline Psychological counseling and accepting cancer diagnosis & $\begin{array}{l}\text { female } \\
\text { male }\end{array}$ & $\begin{array}{l}52(68.4) \\
16(51.6)\end{array}$ & $\begin{array}{l}24(31.6) \\
15(48.4)\end{array}$ & 0.101 \\
\hline $\begin{array}{l}\text { Counseling on treatment and other measures aimed at } \\
\text { preventing liver tumors }\end{array}$ & $\begin{array}{l}\text { female } \\
\text { male }\end{array}$ & $\begin{array}{l}57(66.3) \\
13(34.2)\end{array}$ & $\begin{array}{l}29(33.7) \\
25(65.8)\end{array}$ & 0.001 \\
\hline Counseling on diagnostic testing options besides genetic tests & $\begin{array}{l}\text { female } \\
\text { male }\end{array}$ & $\begin{array}{l}51(55.4) \\
10(27.0)\end{array}$ & $\begin{array}{l}41(44.6) \\
27(73.0)\end{array}$ & 0.003 \\
\hline Counseling on genetic tests & $\begin{array}{l}\text { female } \\
\text { male }\end{array}$ & $\begin{array}{l}50(53.2) \\
12(33.3)\end{array}$ & $\begin{array}{l}44(46.8) \\
24(66.7)\end{array}$ & 0.043 \\
\hline Prognostication predicting chances of future health & $\begin{array}{l}\text { female } \\
\text { male }\end{array}$ & $\begin{array}{l}46(47.9) \\
14(34.1)\end{array}$ & $\begin{array}{l}50(52.1) \\
27(65.9)\end{array}$ & 0.137 \\
\hline Treatment of such metastatic disease & $\begin{array}{l}\text { female } \\
\text { male }\end{array}$ & $\begin{array}{l}9(47.4) \\
5(33.3)\end{array}$ & $\begin{array}{l}10(52.6) \\
10(66.7)\end{array}$ & 0.409 \\
\hline $\begin{array}{l}\text { Counseling on the nature of ocular melanoma and eye } \\
\text { treatment options }\end{array}$ & $\begin{array}{l}\text { female } \\
\text { male }\end{array}$ & $\begin{array}{r}32(27.8) \\
6(13.0)\end{array}$ & $\begin{array}{l}83(72.2) \\
40(87.0)\end{array}$ & 0.046 \\
\hline Post-treatment care for my overall body/health & $\begin{array}{l}\text { female } \\
\text { male }\end{array}$ & $\begin{array}{l}26(26.8) \\
11(23.4)\end{array}$ & $\begin{array}{l}71(73.2) \\
36(76.6)\end{array}$ & 0.662 \\
\hline Nevus tracking (if applicable) & $\begin{array}{l}\text { female } \\
\text { male }\end{array}$ & $\begin{array}{r}11(23.4) \\
3(18.8)\end{array}$ & $\begin{array}{l}36(76.6) \\
13(81.3)\end{array}$ & 0.969 \\
\hline Support from work/professional community & $\begin{array}{l}\text { female } \\
\text { male }\end{array}$ & $\begin{array}{r}15(19.0) \\
4(11.4)\end{array}$ & $\begin{array}{l}64(81.0) \\
31(88.6)\end{array}$ & 0.468 \\
\hline $\begin{array}{l}\text { Screening tests for tumors in the liver and other parts of the } \\
\text { body }\end{array}$ & $\begin{array}{l}\text { female } \\
\text { male }\end{array}$ & $\begin{array}{r}18(16.5) \\
5(10.9)\end{array}$ & $\begin{array}{l}91(83.5) \\
41(89.1)\end{array}$ & 0.367 \\
\hline Tumor detection & $\begin{array}{l}\text { female } \\
\text { male }\end{array}$ & $\begin{array}{r}19(16.2) \\
5(10.6)\end{array}$ & $\begin{array}{l}98(83.8) \\
42(89.4)\end{array}$ & 0.359 \\
\hline Posttreatment care for my eye & $\begin{array}{l}\text { female } \\
\text { male }\end{array}$ & $\begin{array}{r}16(14.5) \\
6(12.5)\end{array}$ & $\begin{array}{l}94(85.5) \\
42(87.5)\end{array}$ & 0.733 \\
\hline Support from family and friends & $\begin{array}{l}\text { female } \\
\text { male }\end{array}$ & $\begin{array}{l}14(13.5) \\
2(4.5)\end{array}$ & $\begin{array}{l}90(86.5) \\
42(95.5)\end{array}$ & 0.191 \\
\hline Treatment selection & $\begin{array}{l}\text { female } \\
\text { male }\end{array}$ & $\begin{array}{c}14(12.8) \\
3(7.0)\end{array}$ & $\begin{array}{l}95(87.2) \\
40(93.0)\end{array}$ & 0.454 \\
\hline Tumor diagnosis & $\begin{array}{l}\text { female } \\
\text { male }\end{array}$ & $\begin{array}{r}15(12.4) \\
5(10.2)\end{array}$ & $\begin{array}{r}106(87.6) \\
44(89.8)\end{array}$ & 0.688 \\
\hline $\begin{array}{l}\text { Eye conserving therapy (if applicable) (e.g. plaque or proton } \\
\text { beam) }\end{array}$ & $\begin{array}{l}\text { female } \\
\text { male }\end{array}$ & $\begin{array}{r}10(10.3) \\
5(13.2)\end{array}$ & $\begin{array}{l}87(80.7) \\
33(86.8)\end{array}$ & 0.636 \\
\hline $\begin{array}{l}\text { Enucleation process (including care, prosthesis discussions, } \\
\text { etc.) (if applicable) }\end{array}$ & $\begin{array}{l}\text { female } \\
\text { male }\end{array}$ & $\begin{array}{l}0(0) \\
2(15.4)\end{array}$ & $\begin{array}{l}16(100) \\
11(84.6)\end{array}$ & 0.374 \\
\hline
\end{tabular}

Items listed according to level of dissatisfaction in women. ${ }^{a} \chi^{2}$ test. 
(16.1\%), MLPA/MSA by $3(1.7 \%)$, SNP analysis by 1 $(0.6 \%)$ and Foundation 1 testing by $1(0.6 \%)$. Seventy-six $(42.2 \%)$ of 180 patients with uveal melanoma reported that their tumor was not analyzed genetically.

In 51 patients who provided GEP results, class $1 \mathrm{~A}$ was reported by $13(25.5 \%)$ patients, class $1 \mathrm{~B}$ by $16(31.4 \%)$ and class 2 by $22(43.1 \%)$. When patients were asked if they were happy with the additional information provided by GEP, 27 (93\%) of 29 patients with a class 1 melanoma gave a positive response as compared to 18 (82\%) out of 22 with a class 2 melanoma.

\section{Screening for Metastasis}

Liver ultrasonography was reported by 37 (24.3\%) patients, computed tomography (CT) by 95 (52.8\%), magnetic resonance imaging (MRI) by 88 (48.9\%), positronemission tomography scan by 57 (31.7\%), liver function tests by $89(49.4 \%)$ and chest X-ray by $15(8.3 \%)$. Three patients had metastasis on initial screening.

\section{Metastatic Disease}

Metastatic disease was reported by 19 (11.2\%) of 169 respondents. One (7.7\%) out of 13 with a class $1 \mathrm{~A}$ melanoma result developed metastasis, as compared to 0 of 16 patients with a class 1B melanoma and 4 of $22(18.2 \%)$ with a class 2 melanoma.

\section{Physician Experience and Communication}

With regard to communication aids, brochures were mentioned by 84 patients (46.7\%), links to online information by $22(12.2 \%)$, printed internet material by 19 (10.6\%), handwritten notes by $16(8.9 \%)$, links to patient support groups, such as the OMF, by 12 (6.7\%), copy of the medical report by 1 patient, and permission to obtain an audio-recording of the consultation by 1 patient. Sixty-five patients (36.1\%) stated that no aids were provided. Sixty-four $(35.5 \%)$ patients reported that they were informed of the number of patients the ocular oncologist treats annually with the proposed modality.

\section{Psychological Support}

Twenty-four (13.3\%) of 169 respondents reported an offer of psychological support whereas 145 (85.8\%) reported not receiving this support. Twenty-two (22.2\%) out of 99 respondents reported emotional support had been provided when they received a poor prognosis.

\section{Satisfaction with Care Received}

Table 1 summarizes patients' satisfaction with their experience, according to their gender. Most dissatisfac- tion was with financial advice and psychological counseling. Women were most dissatisfied with counseling on financial matters and metastasis prevention.

\section{Need for More Information}

Patients mostly wished for better information on paying for their care and psychological counseling (Table 2). Compared to men, women were more interested in the impact of their disease on activities and quality of life.

\section{Conjunctival Melanoma}

There were 4 patients with conjunctival melanoma (3 women). The tumor was detected by an optometrist in 3 patients and by an ophthalmologist in 1 . Three patients were immediately referred to an ocular oncologist but 1 patient was monitored for over a year. One patient was dissatisfied with the detection process. One patient was satisfied with the information provided. The therapeutic modalities reported to have been received were topical chemotherapy (2), proton beam radiotherapy (2), cryotherapy (1), excision (1), enucleation (1), and exenteration (1). One patient experienced recurrence. One patient reported having GEP of the tumor and 1 reported MLPA/ MSA. Three wanted more information on the impact of the disease on their life. One patient received psychological support. Two patients were offered screening for metastatic disease and 2 developed metastasis.

\section{Patients' Comments}

The questionnaire gave patients the opportunity to provide comments, the most informative of which are listed in the Appendix.

\section{Discussion}

\section{Main Findings}

This study provides insights into the patient's perspective of the care currently received for ocular melanoma in the US. It complements studies published by academics, which report clinical results that indicate what care patients should receive. Deficiencies are highlighted throughout the care pathway. This study should stimulate measures to improve the patient's healthcare experience, well-being, and clinical outcomes.

\section{Strengths and Weaknesses}

The strengths of the study are the large number of patients from across the US and the inclusion of patients treated in a wide variety of units. The questionnaire was 
Table 2. Satisfaction with information

\begin{tabular}{|c|c|c|c|c|}
\hline Information & Sex & $\begin{array}{l}\text { Inadequate } \\
n(\%)\end{array}$ & $\begin{array}{l}\text { Adequate } \\
n(\%)\end{array}$ & $p$ value \\
\hline Psychological counseling & $\begin{array}{l}\text { female } \\
\text { male }\end{array}$ & $\begin{array}{l}95(84.1) \\
30(73.2)\end{array}$ & $\begin{array}{l}18(15.9) \\
11(26.8)\end{array}$ & 0.126 \\
\hline Financial counseling & $\begin{array}{l}\text { female } \\
\text { male }\end{array}$ & $\begin{array}{l}82(82.8) \\
29(85.3)\end{array}$ & $\begin{array}{r}17(17.2) \\
5(14.7)\end{array}$ & 0.738 \\
\hline $\begin{array}{l}\text { How to talk to your children about your cancer } \\
\text { diagnosis }\end{array}$ & $\begin{array}{l}\text { female } \\
\text { male }\end{array}$ & $\begin{array}{l}70(80.5) \\
25(71.4)\end{array}$ & $\begin{array}{l}17(19.5) \\
10(28.6)\end{array}$ & 0.277 \\
\hline $\begin{array}{l}\text { How to talk to friends and family about your cancer } \\
\text { diagnosis }\end{array}$ & $\begin{array}{l}\text { female } \\
\text { male }\end{array}$ & $\begin{array}{l}91(80.5) \\
29(67.4)\end{array}$ & $\begin{array}{l}22(19.5) \\
14(23.6)\end{array}$ & 0.083 \\
\hline $\begin{array}{l}\text { How your cancer diagnosis in general might impact } \\
\text { your vision, health, emotions, job, family life }\end{array}$ & $\begin{array}{l}\text { female } \\
\text { male }\end{array}$ & $\begin{array}{l}98(76.6) \\
25(51.0)\end{array}$ & $\begin{array}{l}30(23.4) \\
24(49.0)\end{array}$ & 0.001 \\
\hline All possible genetic tests and their risks or benefits & $\begin{array}{l}\text { female } \\
\text { male }\end{array}$ & $\begin{array}{l}93(75.6) \\
29(63.0)\end{array}$ & $\begin{array}{l}30(24.4) \\
17(37.0)\end{array}$ & 0.105 \\
\hline What your diagnosis could mean for your children & $\begin{array}{l}\text { female } \\
\text { male }\end{array}$ & $\begin{array}{l}72(74.2) \\
23(59.0)\end{array}$ & $\begin{array}{l}25(25.8) \\
16(41.0)\end{array}$ & 0.08 \\
\hline $\begin{array}{l}\text { How your melanoma might impact your vision, health, } \\
\text { emotions, job, family life }\end{array}$ & $\begin{array}{l}\text { female } \\
\text { male }\end{array}$ & $\begin{array}{l}89(70.1) \\
25(51.0)\end{array}$ & $\begin{array}{l}38(29.9) \\
24(49.0)\end{array}$ & 0.018 \\
\hline What standards of care to expect at each step & $\begin{array}{l}\text { female } \\
\text { male }\end{array}$ & $\begin{array}{l}86(68.3) \\
24(51.1)\end{array}$ & $\begin{array}{l}40(31.7) \\
23(48.9)\end{array}$ & 0.037 \\
\hline $\begin{array}{l}\text { How the different treatments may influence your } \\
\text { quality of life }\end{array}$ & $\begin{array}{l}\text { female } \\
\text { male }\end{array}$ & $\begin{array}{l}85(67.5) \\
22(46.8)\end{array}$ & $\begin{array}{l}41(32.5) \\
25(53.2)\end{array}$ & 0.013 \\
\hline $\begin{array}{l}\text { How the results from different tests may influence your } \\
\text { decision making }\end{array}$ & $\begin{array}{l}\text { female } \\
\text { male }\end{array}$ & $\begin{array}{l}85(66.9) \\
22(46.8)\end{array}$ & $\begin{array}{l}42(33.1) \\
25(53.2)\end{array}$ & 0.015 \\
\hline $\begin{array}{l}\text { The hard statistics and facts around OM including life } \\
\text { expectancy and likelihood of a cure }\end{array}$ & $\begin{array}{l}\text { female } \\
\text { male }\end{array}$ & $\begin{array}{l}78(61.4) \\
24(50.0)\end{array}$ & $\begin{array}{l}49(38.6) \\
24(50.0)\end{array}$ & 0.172 \\
\hline All possible diagnostic tests and their risks or benefits & $\begin{array}{l}\text { female } \\
\text { male }\end{array}$ & $\begin{array}{l}73(56.6) \\
22(45.8)\end{array}$ & $\begin{array}{l}56(43.4) \\
26(54.2)\end{array}$ & 0.202 \\
\hline All possible treatments and their risks and benefits & $\begin{array}{l}\text { female } \\
\text { male }\end{array}$ & $\begin{array}{l}66(52.0) \\
18(36.7)\end{array}$ & $\begin{array}{l}61(48.0) \\
31(63.3)\end{array}$ & 0.07 \\
\hline $\begin{array}{l}\text { Whether their healthcare providers lived up to the } \\
\text { expectations }\end{array}$ & $\begin{array}{l}\text { female } \\
\text { male }\end{array}$ & $\begin{array}{l}53(44.5) \\
16(34.8)\end{array}$ & $\begin{array}{l}66(55.5) \\
30(65.2)\end{array}$ & 0.255 \\
\hline
\end{tabular}

Items listed according to women's dissatisfaction with information. ${ }^{\text {a }} \chi^{2}$ test.

designed by patients, through the OMF, so that topics most relevant to them were investigated.

There are also weaknesses to this study. First, patients' scores do not necessarily reflect the quality of care provided, because patients may lack extensive medical knowledge. For example, some patients screened for metastasis were satisfied with liver function tests and chest radiography, which have low sensitivity and specificity [1]. Nevertheless, the data usefully indicate educational needs requiring attention.
Second, self-selection of participants biased the results. For example, our cohort with uveal melanoma comprised 130 women and 50 men, whereas this tumor is known to affect both sexes in equal numbers [2]. We remedied this by reporting experience and information needs according to gender (Table 1,2).

Third, the reliability of the patients' data is uncertain. For example, patients may have remembered dates and events incorrectly and may have misheard or misunderstood what they were told about tumor dimensions. 


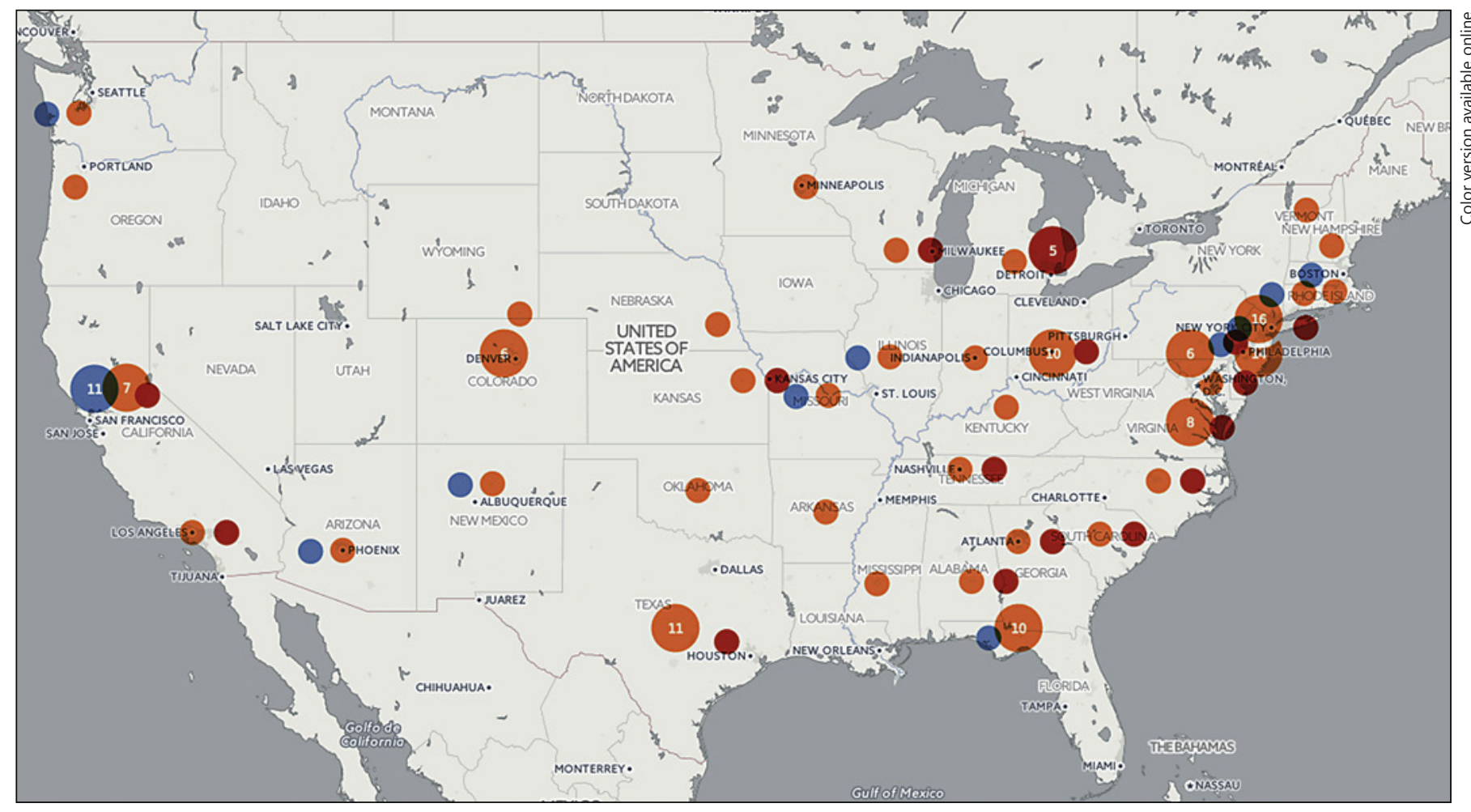

Fig. 1. Treatment selection according to geographic location in the US; plaque brachytherapy (orange), proton beam radiotherapy (blue), and enucleation (red).

\section{Methodology}

Only US patients were included to avoid conflicting data from other countries. It would be interesting to compare patients' experience in different countries.

We did not exclude patients with conjunctival melanoma, because their needs are as great as those with uveal melanoma and their comments equally insightful. Because the two types of melanoma differ greatly, patients with conjunctival melanoma were reported separately. The anecdotal evidence of clinical shortcomings suggests that there is scope for further studies focusing on this group of patients, but with larger numbers.

Caregivers' responses were excluded because of possible bias resulting from "second-hand" information. Comparison of patients' and caregivers' responses is planned.

\section{Clinical Implications}

\section{Detection}

Some reported that their tumor was initially missed. A study of 2,384 patients with uveal melanoma in the UK found that the tumor was missed in $23 \%$ patients, who were more likely to have advanced disease when reaching an ocular oncology center and less likely to retain vision and the eye [3]. Although patients in this study expressed satisfaction with the detection process there is scope for improvement (e.g., mydriasis, examining the entire fundus and not only the "disc and macula," and checking for episcleral sentinel vessels).

\section{Diagnosis}

About a third of patients reported their tumor was initially diagnosed as a nevus. This raises the question as to how many patients did not benefit from color photography, autofluorescence imaging, and optic coherence tomography, possibly because these methods were not widely available when they were investigated.

\section{Primary Ocular Treatment}

The primary treatment was usually brachytherapy. Figure 1 shows great geographic variation in treatment selection, suggesting treatment tends to be selected according to what is available at the treating center rather than according to tumor features. The principle of "Informed consent" dictates that this is acceptable only if patients are counseled about the risks and benefits of all therapies and 
Table 3. Tentative standards of care specific to ocular melanoma

As a patient with ocular melanoma you should expect:

1 To receive a complete eye examination when being screened for ocular disease, with pupil dilatation to make it easier to find any tumor at the back of the eye

2 To be informed of any abnormal findings and their significance, such as the differential diagnosis if a tumor is detected

3 To receive all necessary diagnostic tests (such as color photography, optical coherence tomography, autofluorescence imaging and ultrasonography if there is difficulty distinguishing between nevus and melanoma at the back of the eye)

4 To be given all the information you need to provide fully informed consent for treatment (or nontreatment) of an ocular tumor; this would include information on all therapeutic options, including those not available at your hospital, with an explanation of the risks and benefits of each treatment

5 To be informed of what to expect should you not have treatment

6 To be helped to remember what was said, by means of written and/or audio information

7 To be given sufficient time to decide what to do

8 To have the chance to ask questions

9 To be allowed to have a reasonable number of close relatives or friends with you when discussing your condition with your health provider

10 To be informed of prognostic biopsy and genetic tumor typing, should you have a uveal melanoma, with an explanation of the risks and benefits of this procedure

11 To be informed of your prognosis with respect to your general health and your ocular condition, taking account of how much you wish to know

12 To be informed of the possible impact of your disease and its treatment on your occupation, lifestyle, family, finances and other important aspects of your life

13 To receive adequate counseling, orally or in writing, on how to cope with your disease, how to speak to your relatives and friends about it, how to deal with financial matters relating to your treatment, on any measures that might improve your chances of improving your health and survival prospects, and on other important matters

14 To be informed of any patient advocacy groups

15 To be offered the opportunity of professional psychological support

16 To receive any bad news or stressful information in an appropriate manner

17 To have any procedures performed competently

18 To be informed of any side effects or complications caused by your treatment

19 To be counseled on screening for metastatic disease, with adequate explanation of all tests, including the risks and benefits of each one, and any costs that you may incur

20 To be informed of any clinical trials that may be of relevance to you and to be notified of any sources of information that might be useful

not only those available at the center the patient happens to visit. Such a standard may not be met universally, as suggested by the small proportion of patients receiving information on proton beam radiotherapy.

Few patients reported tumor recurrence and/or secondary enucleation; however, the follow-up time was short, with a median of only 3 years. There is scope for further studies evaluating outcomes after treatment for ocular melanoma across the US. The IRIS Registry of the American Academy of Ophthalmology may in future be useful in this respect [4]. 
Prognostic Biopsy

Few patients expressed satisfaction with counseling on genetic tests, and only $58 \%$ reported that tumor genetics had been performed; however, many patients were treated before the surgical and laboratory techniques reached their present state of development.

Approximately $90 \%$ of patients indicated they were happy with the additional information provided by tumor genetics. This is in keeping with some (but not all) previous studies [5-7]. Further studies are needed.

\section{Screening and Treatment for Metastasis}

The results of this study indicate a wide variety of screening tests for metastatic disease, including insensitive tests (e.g., liver function tests and chest radiography) as well as CT and positron-emission tomography, which expose patients to ionizing radiation [8]. The value of screening has been questioned, because treatment for metastasis only rarely prolongs life $[9,10]$; however, therapeutic methods are advancing rapidly. There is some evidence that screening may nevertheless improve patients' well-being because a normal test result provides reassurance that health is unlikely to deteriorate in the near future. In this study, patients expressed dissatisfaction with metastatic treatment, probably because of the ineffectiveness of such therapy and the high incidence of severe side effects.

\section{Physician Experience and Communication}

Most patients mentioned that they had received a communication aid about their disease. However, only a minority felt that they had received adequate information. We and others at other ocular oncology services provide patients with several communication aids (i.e., audio-recordings of the consultation, information sheets, online information, access to clinical records, telephone helpline run by specialist nurse).

\section{Psychological Support}

This survey suggests a need for improvement in the way that ophthalmologists give patients bad news. There is also evidence of unmet needs for emotional support and psychological counseling from a qualified health professional. More work is needed to identify the best methods for addressing these needs.

\section{Information Needs}

This survey indicates that patients need more information on financial matters, on the likely impact of their tumor on daily life, and on how to talk to children, other relatives, friends, and colleagues about their cancer. These needs could be met by guiding patients to appropriate online information, which is more likely to be readily updated than printed brochures (e.g., American Cancer Society, https://www.cancer.org/cancer.html).

\section{Conclusions}

This study highlights limitations in several aspects of care. There is scope for guidelines similar to those published in the UK and elsewhere for uveal melanoma, retinoblastoma and other malignancies $[11,12]$. On the basis of this study, we tentatively propose a short list of standards of care for patients with ocular melanoma, as a basis for discussion and refinement (Table 3). There is scope for minimum specifications defining the resources that should be available at US centers treating patients with ocular melanoma (e.g., training and qualifications of healthcare providers, equipment, psychological support). This survey also indicates directions for research, education, and other measures to improve the care of patients with ocular melanoma in the US and beyond.

\section{Statement of Ethics}

The study protocol was approved by UCSF's committee on human research and was deemed exempt from need for informed consent, since no patient identifying information was utilized and the survey data provided by the Ocular Melanoma Foundation was anonymous.

\section{Disclosure Statement}

The authors have no conflicts of interest to disclose.

\section{Funding Sources}

Supported in part by That Man May See, Inc., an unrestricted grant from Research to Prevent Blindness, New York, NY, and grant EY002162 (Core Grant for Vision Research) from the National Eye Institute. 


\section{Appendix}

Comments from Patients Participating in Survey Detection

- The fact that my optometrist initially missed the tumor with pupil dilation will never be acceptable to me. It could be seen with the naked eye without dilation just a month later, it was so large.

- I wish the first two eye doctors I saw before the final one would have caught it earlier!

- I wish my optometrist had dilated my eyes regularly. He only does it in people over 50 .

- I wish my optometrist had sent me for tests when I first went to him in 2013 with symptoms of flashing lights. I did not go back to him until a year later when I had symptoms of a detached retina due to the tumor. Early detection could have improved my prognosis.

- My ophthalmologist should have listened to me when I kept telling him there was something wrong with my eye. Instead, he kept telling me that there was nothing wrong, my eye was perfectly healthy and it was just stress. Only when I demanded to see a Retina Specialist, was my ocular melanoma diagnosed.

- I wish that my primary care physician hadn't laughed at me when I voiced my concerns during the visit to get approval to go to the specialist.

- I wish my optometrist told me my nevus needed to be tracked! Had no idea it could become cancerous.

\section{Diagnosis}

- My regular eye doctor could have properly identified it two years before when I was in for my regular eye exam. They actually looked at the eye and told me there was something odd there. Asked lots of questions about family history but said to come back in a year. [They] never once mentioned cancer.

- Original ophthalmologist, experienced with OM, was unable to diagnose even after 6 months of bi-monthly visits. Called me a "diagnostic dilemma." Should have sent me to a specialist sooner.

\section{Consent}

- The main thing I wish had been done differently is that the ophthalmologist who first photographed my nevus should have told me that there was a chance, however small, that it would become a tumor, and that's why I should have it watched. Even though he told me to come back in a year, he basically told me it was nothing to worry about. So, I didn't go back for two years.

- I wish I had been encouraged, given the risks, to treat the "nevus" when it was discovered rather than waiting for 5 years and then finding out it was a class two tumor. The doctors were always so worried about saving my vision. I wish they had been more concerned with saving my life.

- Never heard the word cancer or melanoma at the time of the diagnosis. Was still being referred to as a suspicious nevus. At regular monitoring appointment 6 months later [I] found out that the diagnosis had been updated at [the] previous visit to ocular melanoma. I would have [been] treated 6 months earlier if had known. Love my doctor though and feel in good hands. Not sure why information was not shared previously.
Treatment

- Too little time between diagnosis and treatment to think about potential options.

- I was led to believe I had a benign tumor. Then when definitively diagnosed, I had exactly 30 min to make critical decisions as to treatment.

- It seems each doctor pushes their own agenda. One only does plaque and one only does laser.

- The pain upon waking up back at the hotel after enucleation was something we really weren't adequately prepared for.

- He was great as far as getting the tumor but very unconcerned with the other things that happened with the eye after the tumor was taken care [of].

- The tumor detection and diagnosis scored low because the tumor was detected 2 years prior but wasn't correctly diagnosed. When I was treated at an ocular oncology center 2 years later (Nov 2014), the care was amazing.

\section{Prognostication}

- At my six-week follow-up, after enucleation, my surgeon said twice: "You are cured." I wish I could believe that, but that is not what my research has led me to believe.

- Initial ophthalmologist did not recommend a biopsy; he said it could seed the tumor. I felt his knowledge was not current. This was in 2012.

- I felt pressured by the surgical team at $\mathrm{xxx}$ to not do a Castle Test, and I wish that hadn't happened.

- [It] would have been nice to have been given the option of genetic screening.

- [I wish I had been informed about]: long-term prognosis regarding vision in the treated eye; long-term effects of radiation; size of the tumor; long-term risks of CM [clinical metastasis?]; the impact on lifestyle, work, driving etc.

- [I wish I had] a better understanding of the impact on my career (Registered Dental Hygienist, Periodontal Therapist), and my inability to perform my job adequately, efficiently. [There was] no provision or help for Social Security benefits without a metastatic diagnosis. Now What! Ruined sight, ruined career, ruined financial situation for my family and no idea how long I will be around. These are HUGE concerns, and when I attempt to discuss them, they are sloughed off. Frustrating and make me feel even more lost.

- [I wish I had been told] what to expect going to one eye for vision.

- I wish genetic testing had been discouraged.

\section{Communication}

- Doctor dictated notes over the phone in my presence prior to discussing diagnosis with me directly.

- At initial diagnosis, the ophthalmologist could have spent more than 5 min with me after announcing that I have cancer. I asked for a follow-up session, saying that I would pay for his time, that I just wanted to ask him questions. He answered three questions (I had pages of them), and said, "You will never be an ophthalmologist no matter how much you read. Either do as I say or leave." I left.

\section{Information}

- I have no doubt my ophthalmologist is expert in what he does. I only wish that he would convey more information. 
- The attending physician gave me too many false hopes of seeing again (since my vision at diagnosis time was very good) if I took his preferred method, not telling me that the plaque therapy might not destroy the tumor outright

- [I] wish I had been better informed about the biopsy. If I had known that it was only $1 \%$ risk I would have gone somewhere to have the testing.

- I think lifestyle options should be addressed, such as nutrition, relaxation methods, stress reduction, etc.

- [It] would have been nice to have been given the option of genetic screening.

- I turned to the internet to determine what I was facing and I believe that while the internet is wonderful to purchase a handbag or new golf club it is the wrong venue to seek out medical information and advice, particularly with something this serious. What I read on the internet both frightened and confused me. I wished that there was someone or some avenue to seek information and counseling.

- Doctor could have had better bedside manner and spent more time with me or offered someone else qualified to answer my questions.

- The communication between the surgeon and my family physicians didn't happen until I asked for it.

- There needs to be an active network that patients sign up for so they are contacted about, for example, a clinical trial that fits their profile.

- I wish I knew more about the various modalities of treatment and given sufficient time to make decisions.

- When I was first being watched ([for] the nevus) I suggested that the fear was this turning into a melanoma. I couldn't get any of my doctors to acknowledge this possibility. I think patients should be told of the risk associated with this type of nevus and given counseling/education at this point.

- I know it was hard to hear and understand the full impact of the diagnosis and treatment while undergoing the actual surgery and pain management. I feel having the process re-explained, a number of times, would have been helpful for me at that time

- [I] was not told of other options of treatment other than plaque nor informed of genetic testing.

- We were told to search "Google" for further information.

- My surgeon led me to believe that once my eye was enucleated, I was home free. He does no follow-up in that respect. He never told me I had a 50\% chance of this [metastasis] happening. $\mathrm{He}$ is arrogant and only cares about the eye and nothing else.

- I was not made to understand that it was cancer we were talking about. The doctor later said he didn't want to scare me. He kept saying, "try not to worry." Then once he said "I would be worried.” Also, he didn't talk about any options.

- [I wish there was] more communication between $\mathrm{xxx}$ and my local doctors.

- Did not hear about possibility of genetic testing until night before surgery and had to make quick call on what to do. Glad I chose to do it.

- [Patients] arrive home without notes or materials and not remembering a single word the doctor had said.

- [I wish I had] explanation of what choices needed to be made and how each would affect my life.

- [I wish doctors would] provide information about emotional/ psychological support or support groups.
- My ophthalmologist was so upset and frightened by what he found, he never really discussed his findings with me. The retina specialist and ocular oncologist were wonderful.

- [I wish my doctor was] less rushed...more personal.

- There should be (online) support groups that patients are directed to which are moderated by PROFESSIONALS who keep the crazy [SIC] off these groups so people can ACTUALLY get help, not feel crushed and abused even MORE!

- I always had someone with me taking notes. 1 also took notes after appointments. What we have written doesn't match what the doctor wrote in my chart.

\section{Psychological Support}

- I had no clue that I was going to receive a devastating diagnosis. The doctor bluntly told me I had a huge ciliary body melanoma and sent me to the waiting room by myself to wait for a referral to the ocular oncologist: no kindness, no support, no concern for what that news meant to me.

- I had great care overall, but it would have even better if I could have been referred to a live or at least online support group.

- I presented a very calm exterior, but I was actually horrified at the prospect of loss of my sight, eye and possibly my life. Also, facial disfigurement was a concern. I wish my doctors had acknowledged how frightening a diagnosis it is.

- I wish I had been offered psychological counseling.

- My diagnosis was communicated in a very clinical manner, with very little compassion shown.

- I was abruptly told that I had a cancer in my eye, that the treatment was to take the eye out, that the doctor had room in his surgery schedule a week from Thursday, and that I was to stop by the receptionist to make the appointment. Nothing more.

- Rude, cold...uncaring doctor. Too clinical with very little support information given at the time. He delivered the news and left the room.

- I was told over the phone in a rather unfeeling way.

- [Suggestions:] [information on] treatment available and genetic testing; encourage psychological counseling to help with the acceptance of our disease and someone to just listen to our fears and concerns; a place where others with our disease can get together so we don't feel isolated and can share our experiences with.

- [Suggestions:] Follow-up phone calls after treatment.

- The doctor just wanted to focus on the eye with cancer not the person with the cancer!

- You get a breast cancer diagnosis and immediately everyone reaches their arms out to you, making you meals, offering to help. You become part of a community. With this - there is no community unless you go online, and find groups - only to discover the various "camps" within this community are divided and competitive and care more about their own group being the "face" of ocular melanoma than they do the actual people who HAVE the cancer.

- The treatment of the disease was excellent. The treatment of the person, how to deal with the cancer diagnosis, could have been much better.

- [Suggestions:] More offer of emotional support, financial guidance, holistic pathways.

- A non-specialist just said "Well you have a tumor and I'm pretty confident that it's cancer." 
- Doctors DO NOT WANT TO TALK TO YOU ABOUT DYING or it's possibility. They don't like to discuss things they cannot fix.

- I had cancer in both eyes. Left eye 1997, right eye 2006. Doctors need to do a better job of dealing with depression.

Screening for Metastasis

- [Suggestion:] Having follow-up MRI's of liver instead of just blood liver function tests.

- [It would have been better] if they approached it from an overall health perspective instead of just dealing with my eye.

- The protocol after the plaque treatment was bloodwork every 6 months and X-ray of lungs every 12 months. I believe the metastasis to the liver would have been found earlier if CT was part of the protocol every 6 months.

- I wish the MDs talked more about ways to monitor the disease, besides CT scans. For instance, doing MRIs, which expose [me to] less radiation.

- I wish my oncologist would approve/order an MRI for surveillance. I have CT of the chest, abdomen and pelvis every 6 months.

- The oncologist I was referred to for follow-up care refused to schedule MRIs - only 6-month ultrasounds since it wouldn't matter when the metastases were found. "Once you have metastasis you're dead anyway." I don't see that doctor anymore.

- Happy with screening done at time of dx but no further screening was recommended except LFT.
Treatment of Metastasis

- [I wish my ophthalmologist had] taken a better biopsy sample for future diagnostic testing.

- My medical oncologist was clueless on OM.

Finance

- My insurance company could have cooperated a little better and not caused delays in approving things.

- There should be a group to help fight insurance when insurance denies payment on treatments.... Having to deal with being screwed by insurance, even when you have it, is just as traumatic as the diagnosis, the fear and concern of leaving your family in financial ruin, etc.

- I wish I knew how to handle the finances better. I am still paying for an MRI that I had last summer at Xxx. It was over $\$ 5,000$. My insurance only paid a fraction of that.

- I wish that physicians would realize that even if a patient survives, their life is changed. I feel like there were so many things I wanted to do, places I wanted to visit, but the expenses (even with insurance) have made me so broke I'll never get to go there. I feel I'll spend the rest of my life working to pay for my cancer treatments. No one understands this.

- I was not offered genetic testing or counseling for either emotional or financial (problems).

Note: Words inserted by the authors are enclosed in square brackets. Grammatical errors have been corrected.

\section{References}

1 Francis JH, Patel SP, Gombos DS, Carvajal $\mathrm{RD}$ : Surveillance options for patients with uveal melanoma following definitive management. Am Soc Clin Oncol Educ Book 2013; 382-387.

2 Damato BE, Coupland SE: Differences in uveal melanomas between men and women from the British Isles. Eye 2012;26:292-299.

3 Damato EM, Damato BE: Detection and time to treatment of uveal melanoma in the United Kingdom: an evaluation of 2,384 patients. Ophthalmology 2012;119:1582-1589.

4 Parke Ii DW, Lum F, Rich WL: The IRIS(R) Registry: purpose and perspectives. Ophthalmologe 2017;114(suppl 1):1-6.

5 Cook SA, Damato B, Marshall E, Salmon P: Psychological aspects of cytogenetic testing of uveal melanoma: preliminary findings and directions for future research. Eye 2009;23:581585 .
6 Hope-Stone L, Brown SL, Heimann H, Damato B, Salmon P: How do patients with uveal melanoma experience and manage uncertainty? A qualitative study. Psychooncology 2015; 24:1485-1491.

7 Schuermeyer I, Maican A, Sharp R, Bena J, Triozzi PL, Singh AD: Depression, anxiety, and regret before and after testing to estimate uveal melanoma prognosis. JAMA Ophthalmol 2016;134:51-56.

8 Wen JC, Sai V, Straatsma BR, McCannel TA: Radiation-related cancer risk associated with surveillance imaging for metastasis from choroidal melanoma. JAMA Ophthalmol 2013; 131:56-61.
9 Augsburger JJ, Correa ZM, Trichopoulos N: Surveillance testing for metastasis from primary uveal melanoma and effect on patient survival. Am J Ophthalmol 2011;152:5-9 e1.

10 Kim IK, Lane AM, Gragoudas ES: Survival in patients with presymptomatic diagnosis of metastatic uveal melanoma. Arch Ophthalmol 2010;128:871-875.

11 Nathan P, Cohen V, Coupland S, et al: Uveal Melanoma UK National Guidelines. Eur J Cancer 2015;51:2404-2412.

12 Canadian Retinoblastoma Society: National Retinoblastoma Strategy Canadian Guidelines for Care: Strategie thérapeutique du rétinoblastome guide clinique canadien. Can J Ophthalmol 2009;44(suppl 2):S1-S88. 